\title{
17. Que Relação Tem Júlio César com a Operação Cesariana?
}

\author{
Joffre Marcondes de Rezende
}

\section{SciELO Books / SciELO Livros / SciELO Libros}

REZENDE, J. M. Que Relação Tem Júlio César com a Operação Cesariana? In: $\grave{A}$ sombra do plátano: crônicas de história da medicina [online]. São Paulo: Editora Unifesp, 2009, pp. 163-169. História da Medicina series, vol. 2. ISBN 978-85-61673-63-5. https://doi.org/10.7476/9788561673635.0018.

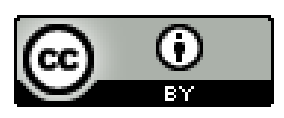

All the contents of this work, except where otherwise noted, is licensed under a Creative Commons Attribution 4.0 International license.

Todo o conteúdo deste trabalho, exceto quando houver ressalva, é publicado sob a licença Creative Commons Atribição 4.0.

Todo el contenido de esta obra, excepto donde se indique lo contrario, está bajo licencia de la licencia Creative Commons Reconocimento 4.0. 


\title{
Que Relação Tem Júlio César com a Operação Cesariana?*
}

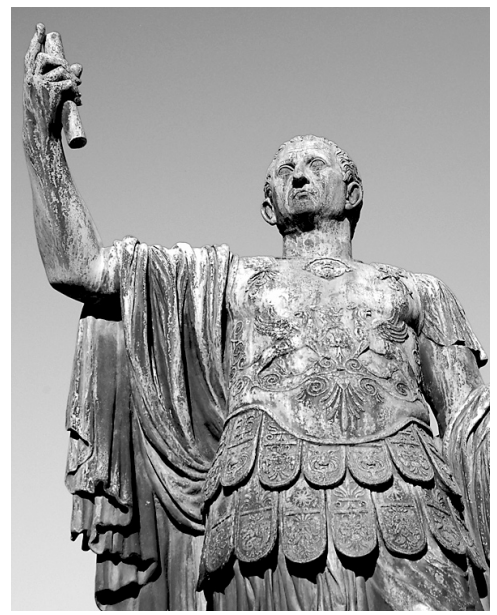

Caio Júlio César (Ioo-44 a.C.).

\begin{abstract}
Caio Júlio César (Gaius Julius Caesar, em latim) foi o primeiro dos doze césares do Império Romano. Antes, apenas um sobrenome de família, Caesar tornou-se um título equivalente ao de imperador, tal foi a destacada atuação e o poder alcançado por Júlio César como general, político, administrador e governante. O título de Caesar passou para o germânico como Kaiser e para o russo como Tzar ou Czar.

Júlio César nasceu em Roma no ano soo a.C. e morreu em 44 a.C., assassinado às portas do Senado Romano, quando os seus partidários tramavam a abolição da República e sua coroação como rei, investido de poder absoluto. Segundo a tradição, Júlio César teria nascido pela abertura do ventre de sua mãe, fato este registrado por Plínio, no século I a.C (Plínio, I979, p. 536).
\end{abstract}

* Apresentado ao x Congresso Brasileiro de História da Medicina. Porto Alegre, 26-29 out. 2005 . 
Desde então estabeleceu-se um vínculo entre Júlio César e a denominação de cesariana ou cesárea dada a esta operação. Duas versões são encontradas na literatura. A primeira, a mais difundida, é a de que o nome da operação teria sido adotado em decorrência de ter Júlio César assim nascido. A segunda atribui o nome de Júlio César ao fato de ele ter nascido por operação cesariana, adjetivo etimologicamente derivado do verbo latino caedo, caedici, caeso, caedere, cortar. Os romanos chamavam de caesares ou caesones aos que eram retirados com vida por abertura da parede abdominal após a morte da mãe. Tanto a primeira como a segunda versão são encontradas em obras de referência das mais acreditadas, como as que citamos a seguir. Veremos mais adiante que ambas as versões são inconsistentes.

Primeira versão:

Cesarian section - In ancient times the procedure was adopted in the case of the death of a pregnant woman in order to save the child if possible. Julius Caesar is said to be born in this manner, hence the name of caesarian section (Skinner, I96I, p. 84).

Cesarian section - In ancient times this was regularly undertaken upon the death of a child-bearing woman near term. Julius Caesar, or more likely one of his antecedents, is said to be born in this manner, hence the eponym (Haubrich, I997, p. 4I).

Caesar's name is also perpetuated in english term cesarean, "the surgical incision of the walls of the abdomen and uterus for the delivery of offspring" (Webster's Word Histories, 1989, p. 99).

Outras fontes registram esta primeira versão, porém colocando em dúvida a sua veracidade:

Caesarian section - Surgical delivery of young through the abdominal wall; so called from the belief (often disputed) that Julius Caesar was born by means of this operation (Barnhart, 200I).

Caesarian section - It is so called, probably incorrectly, from a legend of its employment at the birth of Julius Cesar (Encyclopaedia Britannica, I96I). 
Cesárea, m.q. cesariana - Etim. fr. césarienne [...] do antropônimo Cesar, este sobrenome tem sido vinculado por diversos autores latinos a caesus (a caeso matris utero); donde o substantivo Caesar no sentido de tirar da mãe através de incisão; etim. tida como falsa e/ou popular por outros estudiosos, entre eles Ernout et Meillet (Houaiss e Villar, 200I).

Segunda versão:

Cesarean section - from an unhistorical tradition that the eponymous ancestor of the Roman family Caesar (or Julius Caesar himself) was born by this operation (Morris, I98I).

Césarienne (opération) I 560 . Paré; lat. caesar, enfant mis au monde par incision, decaedere, couper; le surnom Caesar a la même origine (Dauzat, Dubois e Mitterrand, I994).

Caesarea (lat. caedere, cortar); acredita-se que Júlio César assim se tenha chamado por ter nascido por cesariana (Ferreira, I999).

Embora caesar ou caesone designe em latim a criança que veio ao mundo por incisão do abdome e do útero após a morte da mãe, não há nenhuma prova de que o sobrenome Caesar tenha a mesma origem; ele já existia desde Júlio Sexto César (208 a.C.) e o pai de Júlio César tinha o mesmo nome do filho: Caio Júlio César.

Caesar era sobrenome de uma família de nobres patrícios da linhagem Júlia, assim chamada por descender de Julius, filho de Enéas, o herói troiano que emigrou para a região do Lácio após a derrota de Troia, dando início à civilização romana. Enéas era tido como filho da deusa Afrodite (Vênus para os romanos) com um mortal e por isso todos os seus descendentes consideravam-se portadores de sangue divino. O próprio Júlio César refere-se a esta ascendência na oração fúnebre à sua tia Júlia. "Do lado de sua mãe minha tia Júlia descende dos reis; do lado de seu pai está ligada aos deuses imortais [...] os Júlios descendem de Vênus e somos um ramo desta família" (Suetônio, I975, p. 37).

Se Júlio César houvesse nascido por cesariana, teria sido pela morte da mãe durante o trabalho de parto, visto que, na época, a abertura da 
parede abdominal para retirada do feto ainda vivo só era feita após a morte da gestante (Littré, I 898). Tal procedimento é bem antigo na história da humanidade e comum a várias civilizações. Na própria mitologia grega, Asclépio, deus da medicina, veio ao mundo por uma cesárea em sua mãe, a ninfa Coronis, que havia sido morta por Artemis, irmã de Apolo, pai da criança.

No Império Romano, essa prática foi oficializada por uma lei promulgada por Numa Pompílio (7 I 5-673 a.C.), proibindo o sepultamento da mulher grávida sem a retirada do feto.

Embora haja referências a casos isolados de cesarianas em parturientes vivas, antes do século XVI, somente em I $58 \mathrm{I}$, com a publicação do livro de Rousset, intitulado Traité nouveau de l'hysterotomokie ou enfantement césarien, o parto cesáreo passou a ser considerado viável. Neste tratado, o autor relata I 5 casos operados por diferentes cirurgiões nos precedentes oitenta anos (Leonardo, I944, p. 9I). Na maioria das vezes, entretanto, a paciente morria; ou de hemorragia, ou de septicemia. A alta taxa de mortalidade materna somente se reduziu ao final do século XIX após o advento da bacteriologia e a adoção da antissepsia e assepsia em cirurgia.

No relato de Plínio depreende-se que a mãe de Júlio César estaria morta ao ser praticada a cesariana. $O$ trecho que se refere ao episódio tem a seguinte redação: "Auspicatus e necata parente gignuntur, sicut Scipio Africanus prior natus primusque caesarum a caeso matris utero dictus qua de causa et Caesones appellati" (É auspicioso quando a mãe morre durante o parto; assim foi com Scipião o Africano e o primeiro dos Césares, retirado por corte do útero materno; a origem do nome de família é também o mesmo) (Plínio, op. cit.).

A mesma afirmativa encontra-se em Isidoro de Sevilha, em sua obra Etymologias, do século vi d.C., ao discutir a origem da palavra Caesar: "Caesar autem dictus, quod caeso mortuae matris utero prolatus eductusque fuerit, vel quia cum caesarie natus sit" (César foi assim chamado por ter sido extraído após o corte do útero de sua mãe morta, ou então por ter nascido com os cabelos crescidos) (Sanchez Arcas, I950, p. I2).

A afirmação de óbito materno durante o parto não pode ser aceita, porquanto, segundo fontes históricas, Aurélia, mãe de Júlio César, viveu muitos anos após o nascimento do filho. Suetônio, em duas passagens de 
seu livro De Vita Caesarum não deixa a menor dúvida a respeito. Na primeira delas conta-nos que, ao se candidatar ao cargo de sumo pontífice, César dissera a sua mãe que o abraçava: "Eu não entrarei na minha casa, a não ser como pontífice” (Suetônio, op. cit., p. 4I).

$\mathrm{Na}$ segunda passagem, ao relatar a campanha das Gálias, menciona que, no mesmo espaço de tempo, ele perdeu sua mãe, sua filha e pouco tempo depois seu neto (Idem, p. 48).

Segundo transcrição de Pedro Pinto, de um manuscrito do século XIII, intitulado Vida e Feitos de Júlio César, uma compilação de Suetônio, de Lucano e de César, encontra-se o seguinte trecho: "Quando veio o tempo que Caio Júlio César houve de nascer, sua madre arrebentou por uma ilharga e ele saiu por ali e quando nasceu trazia os cabelos muito compridos e lhe puseram o nome de Caesar porque esta palavra quer dizer cabeladura" (Pinto, I944, pp. I I-22).

Este relato, como sugere Pedro Pinto, faz pensar que tenha havido rotura do períneo, mas não do útero, já que a rotura espontânea do útero e, ao mesmo tempo, da parede abdominal, é inverossímil. O mais provável é que o "arrebentamento da madre" tenha sido mal interpretado por Plínio e outros historiadores. Reforça ainda mais este ponto de vista a etimologia dada à palavra Caesar neste texto, relacionando-a com caesaries, cabeleira, e não com a abertura do abdome após a morte da parturiente.

Segundo Ernout et Meillet, apesar da homonímia, o nome de família não se prende ao modo de nascimento de Júlio César, tampouco à cabeleira. Consideram tais étimos de cunho popular e admitem que Caesar tenha sua origem no etrusco. Em seu Dictionnaire étymologique de la langue latine lê-se: "Cesar - surnom d'origine contesté, rattacher par des latins soit a ceasus, 'a caeso matris utero', soit a caesaries. Mais ce sont là des étymologies populaires et Caeser doit être étrusque, comme aisar, dieu" (Ernout e Meillet, I979).

Por sua vez, o termo cesariana existente em latim à época de Júlio César era tão somente o feminino de cesariano, cujo sentido era o de partidário, pertencente, ou relativo a César. A acepção de operação cirúrgica é de data muito posterior.

Em francês foi empregada no vocabulário obstétrico em I 560 por Ambroise Paré, na expressão enfantement césarienne (Robert, I987); em 
inglês há registro em I6I 5 na expressão caesarian section (Oxford English Dictionary, I978). Em português, o primeiro dicionário a registrar cesariana, como termo médico, foi o de Domingos Vieira, elaborado entre i87 I e I874, obra que foi um marco na lexicografia brasileira. É importante assinalar que, no verbete César, são consignadas duas acepções distintas, sem nenhuma conexão entre as mesmas, como segue:

Cesar, s.m. (Do latim caesar, cognome dado às crianças tiradas do seio da mãe por meio da operação depois chamada cesárea ou cesariana, da raiz coed., de coedere, cortar, fazer incisão).

Nome de um caudilho romano que tão grande logar ocupa na história do mundo, que conquistou as Gállias, derrotou Pompeu e se fez senhor da república romana (Vieira, I87I-I874).

Embora cesariana, como termo médico, tenha sido averbada pela primeira vez no dicionário de Domingos Vieira, o referido termo já vinha sendo usado no vocabulário médico da língua portuguesa. Entre i 844 e I 862 foram defendidas três teses inaugurais, sendo duas na Bahia e uma no Rio de Janeiro, que empregaram, no título, a palavra "cesareana". Outras duas do mesmo período preferiram a denominação de "gastro-hysterectomia" em lugar de "cesareana" (Magalhães, I922).

A primeira operação cesariana realizada no Brasil é creditada a José Correia Picanço e teria sido realizada em Pernambuco em i 822. A crônica não esclarece se foi em parturiente viva e se a mesma sobreviveu. A segunda teria sido praticada por Jeronymo Alves de Moura, que foi cirurgião-mor do Hospital da Misericórdia no Rio de Janeiro, de I8I 5 a I833, quando faleceu. Também não há documentação sobre este caso.

Em I 855, no Rio de Janeiro, Luiz da Cunha Feijó, visconde de Santa Izabel, realizou a operação em uma gestante, por desproporção feto-pélvica, nascendo o feto vivo e morrendo a mulher poucos dias depois. Esta operação foi divulgada na ocasião como sendo a primeira cesariana que se fazia no Brasil (Idem). 


\section{Referências Bibliográficas}

BARnhART, R. Chambers Dictionary of Etymology. Edinburgh, Chambers Harrap, $200 \mathrm{I}$.

Dauzat, A.; Dubois, J. \& Mitterrand, H. Nonveau dictionnaire étymologique et historique, $3^{\underline{a}}$ ed. Paris, Larousse, I994.

ENCYCLOPAEDia BRITANNICA. Chicago, I96I.

Ernout, A. \& Meillet, A. Dictionnaire étymologique de la langue latine. Histoire des mots, $4^{\underline{a}}$ ed. Paris, Klincksieck, I979.

Ferreira, A. B. H. Novo Dicionário da Língua Portuguesa, $3^{\underline{a}}$ ed. Rio de Janeiro, Nova Fronteira, I999.

Haubrich, W. Medical Meanings: A Glossary of Word Origins. Philadelphia, American College of Physicians, I997.

Houaiss, A. \& Villar, M. S. Dicionário Houaiss da Língua Portuguesa. Rio de Janeiro, Objetiva, 200I.

Leonardo, R. A. History of Gynecology. New York, Froben Press, I944.

LitTré, E. Dictionnaire de médecine, de chirurgie, de pharmacie, de l'art vetérinaire et des sciences qui s'y rapportent, I $8^{\mathrm{a}}$ ed. Paris, Librarie J.B. Baillière et Fils, I 898.

Magalhães, F. A Obstetrícia no Brasil. Rio de Janeiro, Ed. Leite Ribeiro, I922.

Morris, W. The American Heritage Dictionary of English Language. Boston, Hough Mifflin Co., I98I.

Oxford English Dictionary (Shorter), $3^{\text {a }}$ ed. Oxford, Claredon Press, i 978.

Pinto, P. A. Vocábulos Médicos e de Outra Natureza. Rio de Janeiro, Ed. Científica, I944.

Plínio. Naturalis Historia. The Loeb Classical Library, vol. 2, Cambridge, Harvard University Press, I979.

Robert, P. Dictionnaire alphabétique et analogique de la langue française. Paris, Dictionnaires Le Robert, 1987.

SAnchez Arcas, R. Historia de la Operación Cesarea en España. Madrid, Marban, I950.

Skinner, H. A. The Origin of Medical Terms, $2^{\underline{a}}$ ed. Baltimore, Williams, Wilkins, I96I.

Suetônio. Vies des douze Césars. Paris, Gallimard, I975.

Vieira, D. Grande Dicionário Portuguez ou Tesouro da Lingua Portugueza. Porto, Ernesto Chardron e Bartholomeu H. de Moraes, I87I-I 874.

WEBSTER'S Word Histories. Springfield, Merriam-Webster Inc., I989. 
